\section{Cultivation of Bulbs}

DuRING recent years, bulbs have become a field crop of considerable importance, especially in the Scilly Isles, Cornwall, and Lincolnshire, and growers, or intending growers, will welcome the illustrated bulletin No. 44, entitled "Narcissi Culture ", recently issued by the Ministry of Agriculture (H.M. Stationery Office, $9 d$.). Although bulbs grow well on a number of soils, good drainage and cultivation are essential, but the direct application of fresh manure should be avoided. Potatoes which have been adequately manured leave the soil in excellent condition for bulbs. Among some of the more important questions upon which advice is given are those relating to grading, lifting, storage, and planting. Eelworm has become a serious menace to the bulb-grower, and sterilisation by means of hot water (three hours' immersion at $110^{\circ} \mathrm{F}$.) is strongly advocated, the treatment being given when the bulbs are in as dormant a condition as possible, or injury may result. As regards flowers, while good grading, bunching, and packing are essential, the importance of making the flowers look attractive by means of details such as packing-paper should not be overlooked. Although this trade in narcissus flowers has increased so enormously, the allied bulbgrowing industry could become one of even greater financial importance, for the sum spent annually on imported bulbs amounts to nearly $£ 1,500,000$.

\section{Manures and Manuring}

IT is recognised that owing to the variation in local conditions, it is impossible to give a complete guide to manuring on every farm. Still, the information supplied in Bulletin No. 36, entitled "Manures and Manuring ", which has recently been issued by the Ministry of Agriculture to replace the sectional volume of Leaflets No. 8 on the same subject, the text having been considerably revised by Mr. H. V. Garner (H.M. Stationery Office, price 1s. 3d. net), should be of the utmost value to farmers, if they are to derive the fullest benefit from the money spent on fertilisers. The Bulletin is divided into three parts, the first of which deals with organic manures. In spite of the recent great development in artificial fertilisers, farmyard manure is still the stand-by of arable farmers, but although it is by far the most important type of organic manure, the value of other materials such as liquid manure, town refuse, poultry manure, and seaweed is evidently considerable. Part ii. is devoted to artificial fertilisers. The various types of nitrogenous, phosphatic, and potash manures now on the market are described, while a further section deals with the use of compound manures. The third part supplies useful information with regard to the purchase and use of artificial fertilisers, and enables the farmer to determine the comparative value and costs of nitrogen, phosphoric acid, and potash in the different forms without difficulty. Some suggestions are made, on quite general lines, as to the treatment of farm crops, and a further section is devoted to a discussion of soil analysis and its bearing on cropping and manuring.

No. 3257, VoL. 129]

\section{Improvements in Epidiascopes}

RECENT developments in the design of instruments for the projection of opaque objects have been directed towards increasing the intensity of light directed on the object, improving the quality of the projection lens, and simplifying the mechanical construction in order to ensure lightness, durability, and ease of manipulation. An active part in the development and perfecting of such instruments has been taken by Messrs. Newton and Co. of 72 Wigmore Street, London, W.1. Since the production of their first episcope in 1916, the efficiency and convenience of succeeding models have increased with each stage of development. The high efficiency of their latest types is due largely to the use of special diffusion reflectors. The illuminant is a single 500-watt gasfilled lamp which is so placed that four of these reflectors can be used to concentrate the light on the object and give a uniform illumination over the whole field, an area 6 in. $\times 6$ in. This arrangement, combined with a large aperture projection lens, provides an illumination on the screen equal to that obtained from earlier instruments employing two lamps. As only one lamp is used and the lamp-house well ventilated, the objects are not exposed to any great heat. When it is necessary to keep them at room temperature a ventilating fan can easily be fitted. The silver-surfaced reversing mirror is mounted outside the lamp-house and, consequently, is not subjected to heating from the lamp. The construction of the body, which is of cast aluminium, is such as to ensure lightness and durability; and the design of the instrument renders its operation extremely simple. Precise and easy adjustments are provided for all necessary movements. Instruments of different sizes, embodying these improvements, are available with working distances ranging from $16 \mathrm{ft}$. to $40 \mathrm{ft}$.

\section{Electrical Conveyors in Mines}

IT is generally admitted that the only real way to increase the prosperity of a coal mine is to increase the output per head of the workers employed. Of recent years great improvements have been made in the methods of the removal of the coal broken at the working face by mechanical conveyors actuated by electric motors. The Metropolitan-Vickers Electrical Company has specialised in the production of motors and control gear for this purpose. In the December issue of the firm's Gazette, an account is given of the many rigorous conditions these motors have to satisfy and the various types of conveyor used in practice. In the belt conveyor the coal is carried on a moving continuous belt. In the shaker conveyor it is conveyed by an oscillating trough, which moves slowly in one direction but has a comparatively quick return. The coal is thus carried forward in the desired direction by a series of jerks. In the scraper conveyor the coal is conveyed by a continuous scraper working in a fixed trough. For each type of conveyor the demands on the electrical motor are different and so also are the arrangements of the electrical control equipment. Graphs are given, showing how the loads on these types 